\section{Ongoing developments in psychiatry in Bangladesh}

The Institute of Postgraduate Medicine and Research now runs a three-and-a-half years course in psychiatry that parallels the British MRCPsych and confers the title FCPSpsych from the College of Physicians and Surgeons in Dhaka. So far the number of trained fellows is only of the order of two to three per year.

The final MB examination now contains compulsory psychiatry questions. It is hoped that this will encourage medical students to investigate a career in psychiatry and help with the current shortage of trained staff. A re-orientation course for GPs who wish to specialise in psychiatry is also now available at the Institute of Mental Health and Research.

The country aims to have a trained psychiatrist in each of the 64 districts to act as a referral centre for physicians and primary care workers and to be responsible for the development of mental health services in his own region.

Finally, Bangladesh is investing a great deal of its resources in the recruitment and training of family welfare workers who will operate at the village level and will be involved in the identification and diagnosis of psychiatric cases, their referral to district specialist services and follow-up.

\title{
The times
}

\section{Community care: Italy's 'U' turn}

\section{Henry R. Roluin, Emeritus Consultant Psychiatrist, Horton Hospital, Epsom, Surrey}

Give or take a few months, it must be 20 years since I led a College Study Tour Group on a tour of Italy, or, to be more exact, of the area north of Rome, economically privileged and steeped in the academic tradition from the Renaissance onwards.

Each and every city we visited had a magic all of its own - Verona, Padua, Venice, Gorizia, Trieste and Bologna. The hospitality was unforgettable: the official banquets, of which there were several, were occasions for self-indulgence on a Babylonian scale. But study tours, even Italian study tours, are not organised in order to furnish the participants with a Roman holiday. There was work to be done.

We visited a range of psychiatric facilities under the auspices of different university departments. From a clinical standpoint, there was little cause for surprise. Italian schizophrenic patients, or those with learning disability, are indistinguishable from their British counterparts, although it came as a surprise to see them nursed together, not only in the same hospi- tals, but in the same wards. There were, however, obvious differences in management, particularly marked in the use of physical restraint in patients who, we were told, were a danger to themselves or others.

However, what struck us smartly between the eyes was the dramatically changed concept of mental illness in certain areas of Italy together with the changed role of the psychiatrist himself. It was all too apparent that these changes stemmed from the political thinking of individual psychiatrists, or were a reflection of the political climate of the area concerned. At at least two meetings it was in the context of politics rather than psychiatry that discussion became heated, if not red-hot. At one our host was none other than the late Professor Franco Basaglia, an aristocrat by birth and a Marxist by conviction. He wore an air of superiority tinged with arrogance reflecting both these threads in his make-up. But in spite of, or, indeed, because of these traits, he was at 
that time a most powerful, if not, the most powerful figure in Italian psychiatry. He had played a central role in persuading his government to introduce Law 180, a law which caused mental hospitals to close and to discharge their patients willy-nilly into the community. At our meeting, Professor Basaglia paraded his Marxism and made no bones about the use of Marxist ideology in handling the problems of mental disorder.

At the other meeting there was no outright declaration of political affiliations, but they obtruded nevertheless. In theory and in practice the work carried out by the department was governed by a bizarre blend of Marxist dialectic and Freudian psychoanalysis seasoned to taste with sprinklings of R. D. Laing, David Cooper, Thomas Szasz and others of that anti-psychiatry galère. It was evident that as a spin-off from this concoction, genetics were out and environmentalists were in: it was not the individual who was sick, only the society in which he had the misfortune to live. As a corollary, the argument went on, mental disorder must be treated in the community by social agents who may or may not be doctors, let alone psychiatrists. It was evident, too, that mental disorder was considered as a single entity in the same way as pears and pineapples can be lumped together as fruit. Classification, it seemed, was unimportant as was the training (if any) of those who leaped on the therapeutic band-wagon.

As luck would have it, we were treated to a superlative exposition of the mess that psychiatry, or, rather, anti-psychiatry had got itself into in this particular neck-of-the-woods. One of our party insisted on an answer to the sort of dilemma which arises from time to time in any community. He described a situation occasioned by a manic patient wielding an axe and threatening the lives of his family. How would the Crisis Intervention Unit deal with it? The reply that tripped off the tongue like a child reciting its catechism was that the first necessity would be to resolve the counter-transference! There was a stunned silence followed after an interval by hoots of derisive laughter, echoes of which will live with me for the rest of my days.

Despite these patent lunacies, Law 180 , passed in 1978, had been enacted: the majority of Italy's mental hospitals, with a patient population of some 60,000 , were duly closed without, tragically, the provision of anything like adequate facilities in the community. The result was predictable: there was chaos. Apart from a spate of suicides and deaths from starvation, a new class of vagrant was created - the abandonati.

But the lunacy which inspired the 'fiasco' in Italy had its equivalent in other so-called civilised countries. In the USA, for instance, the dire situation which ensued prompted Dr Alan A. Stone, Professor of Law and Psychiatry at Harvard (Law, Psychiatry and Morality, American Psychiatric Press, 1984) to write: "Yet madness has not gone out of the world as was hoped, in fact, madness is more visible than ever in this country. One can see chronic mental patients in the streets of every major city in the United States." Nor can this country escape the most severe censure. What can be seen in New York, Boston, Chicago and Los Angeles can be seen in equal measure in London, Birmingham, Liverpool and Leeds. It could well be becoming worse, to judge by the ever-increasing attention of the media in recent months to the disgraceful dearth of community care for those desperately dependent patients discharged from our disappearing mental hospitals. The situation has been highlighted recently by the muchpublicised case of Ben Silcock, a hapless, homeless schizophrenic who at the London Zoo tried to emulate the lion-resistant powers of Daniel with near fatal results.

But there is hope. The report from the British Medical Journal's Rome correspondent, Chris Endean (BMJ, 306, 6 March 1993, p. 605), entitled, 'Italy retreats from community care for mentally ill', brought tears of joy to my ageing eyes as it must have done to other psychiatrists, who, like myself, have been banging the drum on behalf of the destitute, chronic schizophrenic for decades.

Incidentally, at great expense, I am having a plaque cut to hang in my study on which will be writ in letters of gold the inspired words of Guiliano Amato, Italy's prime minister, who described the supporters of Basaglia's theory on insanity as "a species close to extinction but not worth saving."

Are you listening, Mrs Bottomley? 